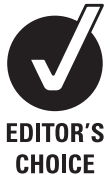

Edward S Harkness Eye Institute, Columbia University Medical Center, New York, New York, USA

\section{Correspondence to} Dr Stanley Chang, Edward S Harkness Eye Institute, Columbia University Medical Center, 635 West 165th Street, New York, NY 10032, USA; sc433@columbia.edu

Accepted 25 October 2009 Published Online First 9 September 2010

\title{
Combined arteriovenous sheathotomy and intraoperative intravitreal triamcinolone acetonide for branch retinal vein occlusion
}

\author{
John C Hwang, Susan K Gelman, Howard F Fine, Stanley Chang, Lucian V Del Priore
}

\begin{abstract}
Purpose To describe the treatment of macular oedema secondary to branch retinal vein occlusion (BRVO) with concomitant pars plana vitrectomy/arteriovenous sheathotomy and intraoperative intravitreal triamcinolone acetonide.

Methods Retrospective case series.

Results Four eyes of four patients were identified. Patients improved from a mean best-corrected visual acuity of 20/124 at baseline to 20/122 at month 1, 20/83 at month 3, 20/74 at month 6, 20/59 at month 9 and 20/44 at month $12(p=0.01)$. All patients demonstrated improvement in visual acuity and macular oedema on fluorescein angiography and/or optical coherence tomography (OCT).

Conclusion For patients with persistent macular oedema due to BRVO refractory to pharmacotherapy and/or laser photocoagulation, concomitant pars plana vitrectomy with arteriovenous sheathotomy and intravitreal triamcinolone may improve best-corrected acuity and reduce macular oedema on fluorescein angiography and OCT.
\end{abstract}

Branch retinal vein occlusion (BRVO) is the second most prevalent retinovascular disease following diabetic retinopathy, and typically affects patients 50 years of age and older. ${ }^{1}$ BRVO usually has a favourable natural history, as approximately $60 \%$ of patients retain 20/40 vision or better. ${ }^{2}$ However, in many cases there is significant and sustained vision loss due to disease sequelae that include macular oedema, macular ischaemia, vitreous haemorrhage, secondary neovascularisation, serous retinal detachment, traction retinal detachment, traction-rhegmatogenous retinal detachment and capillary non-perfusion. ${ }^{3}$ A variety of treatment modalities have been explored, including laser photocoagulation, intraocular corticosteroid injections, limited arteriovenous-crossing manipulation without pars plana vitrectomy, pars plana vitrectomy alone, intravitreal injection of anti-vascular endothelial growth factor (VEGF) drugs and arteriovenous sheathotomy with or without pars plana vitrectomy. ${ }^{1-5}$ This report describes four patients who underwent vitrectomy and arteriovenous sheathotomy combined with intraoperative intravitreal triamcinolone acetonide for the treatment of persistent macular oedema due to BRVO.

\section{MATERIALS AND METHODS}

The study adhered to the tenets of the Declaration of Helsinki and received approval by the institutional review board of New York Presbyterian Hospital (New York). Medical records of patients who underwent concomitant pars plana vitrectomy with arteriovenous sheathotomy and intraoperative intravitreal triamcinolone acetonide for the treatment of macular oedema due to BRVO from December 2002 to December 2008 at Columbia University Medical Center's Edward S Harkness Eye Institute were reviewed retrospectively in compliance with the Health Insurance Portability and Accountability Act. Data abstracted included patient demographics, ocular history and Snellen bestcorrected visual acuity (BCVA) immediately before surgery and at postoperative months 1, 3, 6, 9 and 12. Optical coherence tomography (OCT) and fluorescein angiography images were reviewed in an unmasked, qualitative fashion. Visual acuity data were converted to logarithmic minimal angle resolution (logMAR) before analysis. Descriptive statistics and Student's t test for paired samples were used as appropriate.

All patients signed written, informed consent before surgical intervention. All vitrectomy procedures were performed by one of two surgeons (SC, LVDP) with the Alcon Accurus Vitrector (Alcon, Fort Worth, Texas, USA) and a disposable 25-gauge trocar/cannula system. Arteriovenous sheathotomy procedures were performed with a bent microvitreoretinal blade to lyse the adventitial sheath and separate the overlying artery from the vein at the site of occlusion. All patients received an intravitreal injection of $0.1 \mathrm{ml}$ of a $40 \mathrm{mg} / \mathrm{ml}$ suspension of triamcinolone acetonide (BristolMyers Squibb, Princeton, New Jersey, USA).

\section{RESULTS}

\section{Case 1}

A 42-year-old man was diagnosed with an inferotemporal vein occlusion of the right eye with a BCVA of 20/100. Fluorescein angiography revealed occlusion of the inferotemporal vein at the site of an arteriovenous crossing and extensive macular oedema (figure 1). Macular oedema worsened over the first month and BCVA decreased to 20/150. Inferior sectoral panretinal photocoagulation was performed and BCVA improved transiently to $20 / 80$ but subsequently declined to $20 /$ 100 with recurrence of macular oedema. Because the site of the venous obstruction was identified, the patient underwent a 25-gauge pars plana vitrectomy with arteriovenous sheathotomy and intravitreal injection of $4 \mathrm{mg}$ of triamcinolone acetonide approximately 6 months after initial presentation 

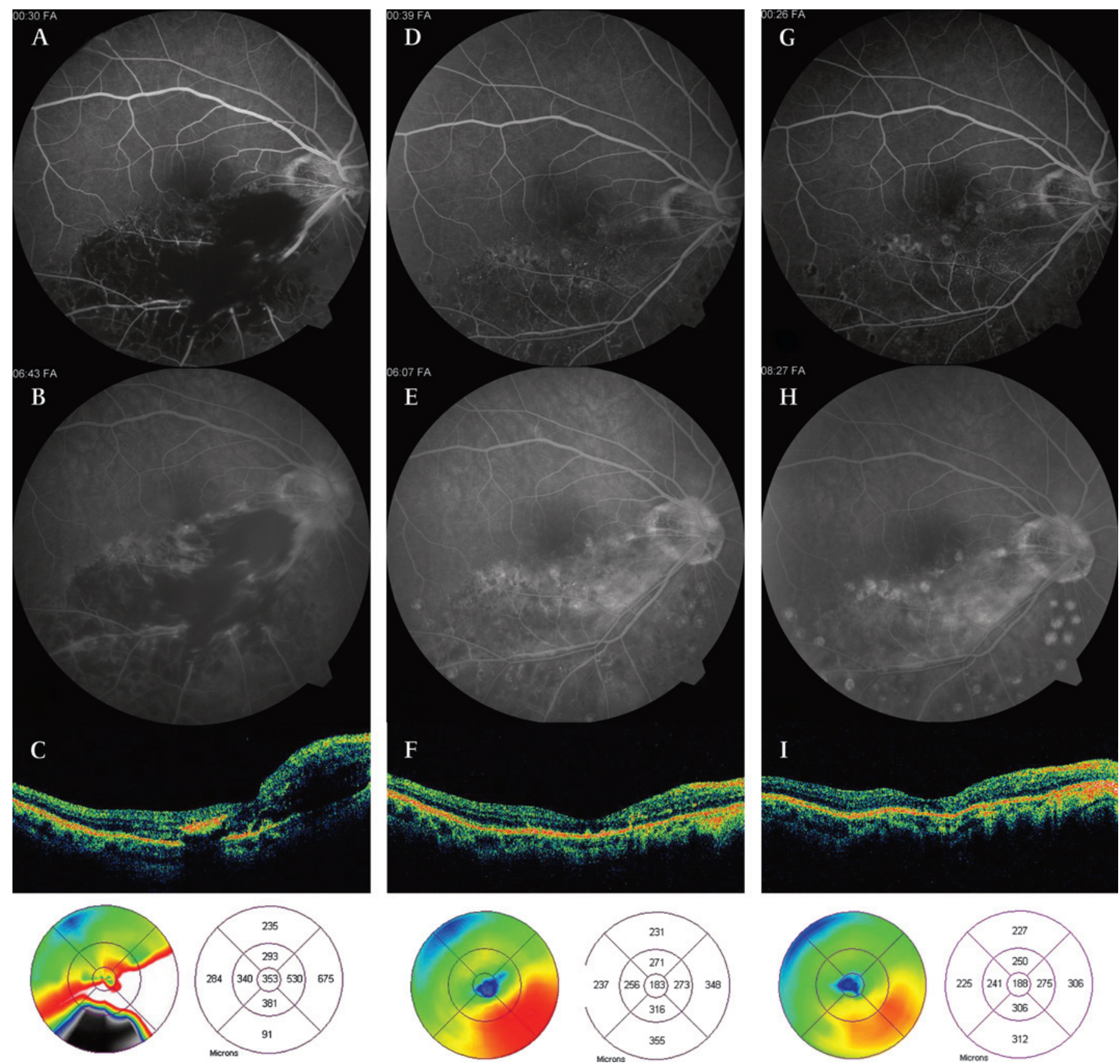

Figure 1 Case 1. $(A, B)$ Preoperative fluorescein angiography reveals inferotemporal branch retinal vein occlusion with active leakage and extensive intraretinal haemorrhage and (C) optical coherence tomography (OCT) demonstrates macular oedema in inferior half of the macula (best-corrected visual acuity (BCVA) 20/100). Inferior scatter photocoagulation was applied preoperatively without significant improvement in visual acuity. Three months after sheathotomy and intravitreal triamcinolone acetonide, $(\mathrm{D}-\mathrm{E})$ there is marked decrease in haemorrhage and fluorescein angiography demonstrates less leakage and (F) OCT shows significant resolution of the oedema. Nine months postoperatively, $(\mathrm{G}, \mathrm{H})$ fluorescein angiography and (I) OCT demonstrate continued improvement in macular oedema (BCVA 20/30).

Six months postoperatively, BCVA improved to $20 / 40$ and dilated funduscopic examination revealed no lipid, haemorrhage, or macular oedema. Fluorescein angiography and OCT revealed resolution of cystic macular oedema. The patient's BCVA continued to improve and measured 20/30 2 years postoperatively.

\section{Case 2}

A 60-year-old man was diagnosed with a superotemporal BRVO and cystoid macular oedema in the right eye. Over the following 3 years, the patient underwent a total of five argon sectoral panretinal photocoagulation treatments and an intravitreal injection of $4 \mathrm{mg}$ of triamcinolone acetonide. Despite treatment, the patient had a persistent BCVA of 20/60 due to chronic, recurrent cystoid macular oedema and persistent BRVO. Fluorescein angiography demonstrated cystoid macular oedema, collateral vessel formation and laser photocoagulation lesions (figure 2).

The patient underwent 25-gauge pars plana vitrectomy, arteriovenous sheathotomy, intravitreal injection of $4 \mathrm{mg}$ triamcinolone acetonide, and cataract extraction by phacoemsulification with placement of a posterior chamber lens. One 

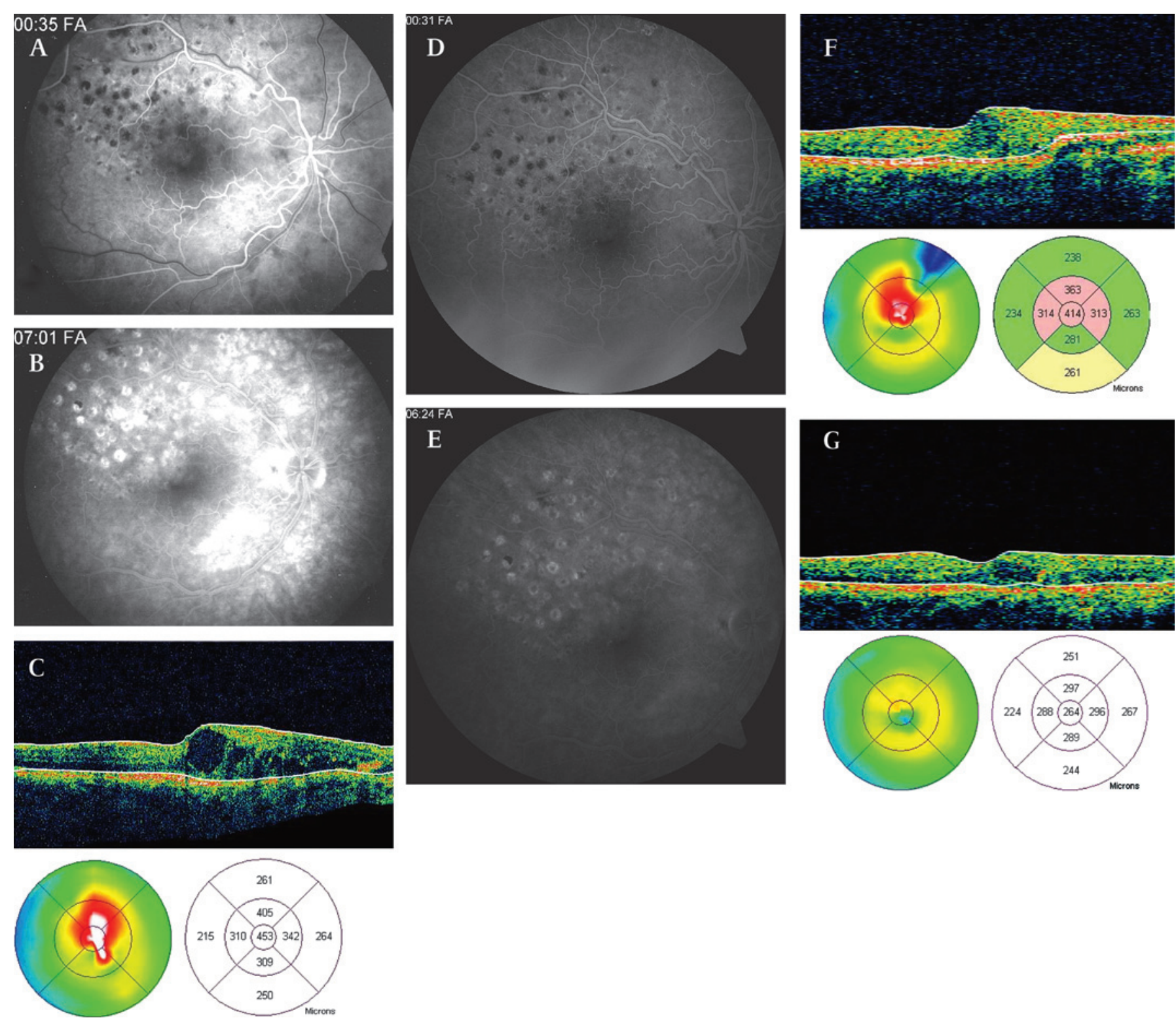

Figure 2 Case 2. $(A, B)$ Preoperative fluorescein angiography reveals superotemporal branch retinal vein occlusion with persistent cystoid macular oedema despite treatment with laser photocoagulation (best-corrected visual acuity (BCVA) 20/60) and (C) optical coherence tomography (OCT) confirms intraretinal oedema. One month after sheathotomy and intravitreal triamcinolone acetonide, (D,E) fluorescein angiography and (F) OCT demonstrate regression of oedema. One year postoperatively, (G) OCT reveals resolution of macular oedema (BCVA 20/30).

year postoperatively, BCVA was 20/30 and 2 years later BCVA measured 20/20. OCT was notable for complete resolution of macular oedema.

\section{Case 3}

A 74-year-old woman with no significant past medical history was diagnosed with a superotemporal BRVO in the left eye, with BCVA of 20/100. Past ocular history was significant for exudative age-related macular degeneration in the right eye with submacular scarring and BCVA of count fingers at $6 \mathrm{ft}$. Fluorescein angiography demonstrated significant leakage in the area of the vein occlusion and OCT demonstrated significant macular oedema (figure 3). One week after diagnosis, she underwent 25 gauge pars plana vitrectomy with elevation of the posterior hyaloid, peeling of the internal limiting membrane and arteriovenous sheathotomy at the site of occlusion. Intraoperative sectoral panretinal photocoagulation was performed in the area of venous occlusive disease to eliminate regions of ischaemic retina that may be a source of VEGF and thereby a potential contributor to macular oedema. This was followed by an intravitreal injection of $4 \mathrm{mg}$ triamcinolone acetonide.

Three weeks postoperatively, the patient noted a marked subjective improvement in her visual field and dilated fundus examination revealed improvement of macular oedema. One year postoperatively, BCVA measured 20/40. OCT and fluorescein angiography showed a marked decrease in macular oedema.

\section{Case 4}

A patient was diagnosed with a superotemporal BRVO in the right eye with BCVA of count fingers at $3 \mathrm{ft}$. Funduscopic examination and OCT were significant for marked oedema and haemorrhage in the macula. The patient underwent intravitreal injection of $4 \mathrm{mg}$ triamcinolone acetonide and BCVA subsequently improved to 20/400. The patient's visual acuity 
Figure 3 Case 3. (A,B) Preoperative fluorescein angiography demonstrates superotemporal branch retinal vein occlusion with extensive leakage and (C) optical coherence tomography (OCT) reveals a significant increase in central retinal thickness (best-corrected visual acuity (BCVA) 20/100). (D) Postoperative OCT 3 years after sheathotomy, intravitreal triamcinolone acetonide and superior panretinal photocoagulation demonstrate improvement in macular oedema (BCVA 20/40). Mild foveal atrophy is present.
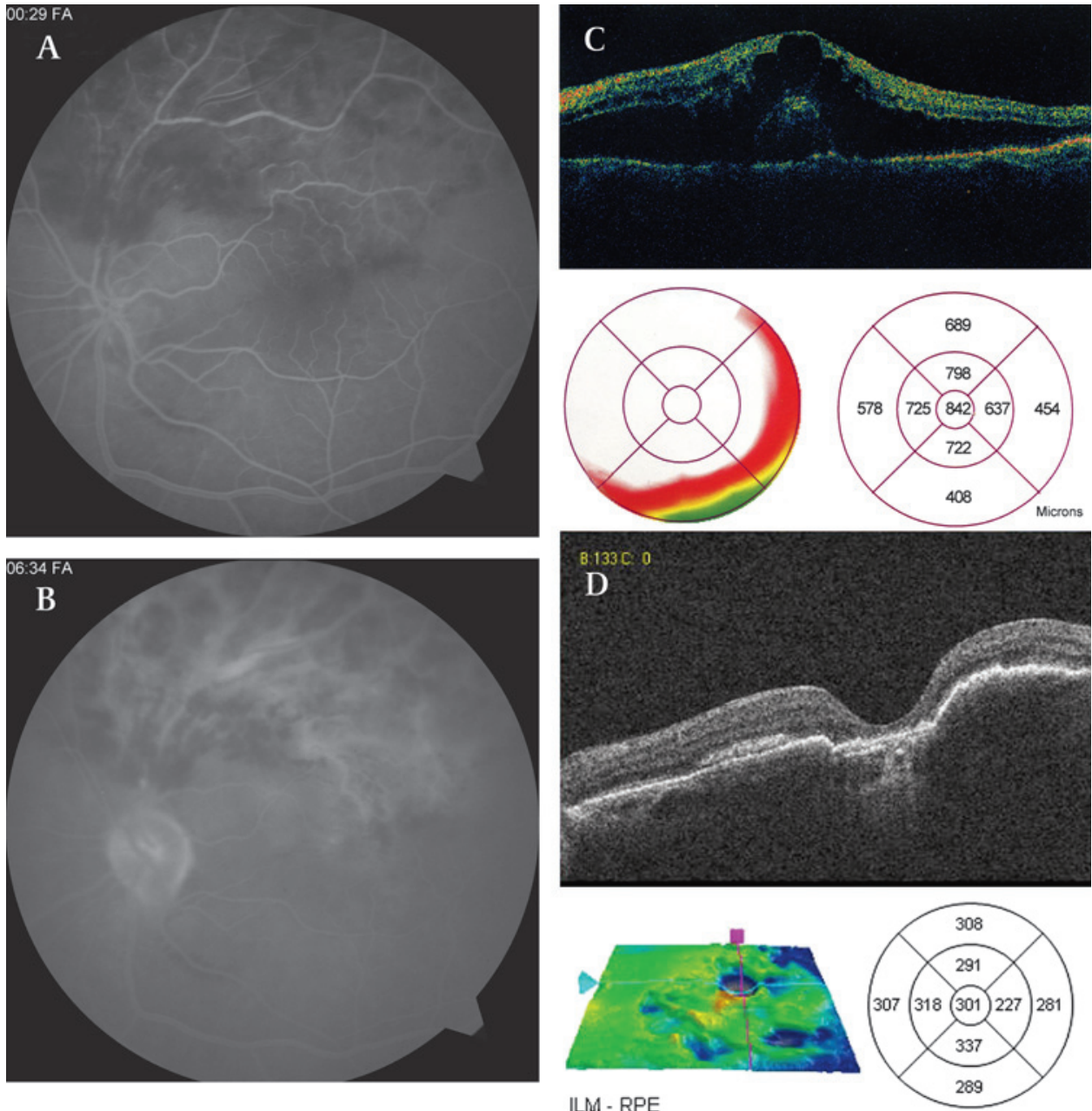

ILM - RPE

ILM-RPE Thickness (um) remained stable over the following 5 months without improvement and the patient underwent 25-gauge pars plana vitrectomy, peeling of the internal limiting membrane, arteriovenous sheathotomy and intravitreal injection of $4 \mathrm{mg}$ triamcinolone acetonide.

Two months postoperatively, BCVA improved to 20/80. Funduscopic examination and OCT revealed improvement of macular oedema. One year postoperatively, BVCA remained stable at 20/80, but improved to 20/60 after cataract extraction by phacoemsulification with the placement of a posterior chamber lens.

\section{DISCUSSION}

This case series demonstrates the efficacy of concomitant arteriovenous sheathotomy and intraoperative intravitreal triamcinolone acetonide in the treatment of BRVO with persistent macular oedema and limited visual acuity. In this study, two patients had BCVA of 20/100 or less for four or more months despite laser treatment and/or pharmacotherapy, one patient had BCVA of 20/100 in the dominant eye and one had BCVA of 20/60 for more than 3 years despite laser treatment and pharmacotherapy. All patients were treated with combination therapy of vitrectomy and arteriovenous sheathotomy plus intravitreal triamcinolone acetonide injection, and all achieved favourable outcomes. One year postoperative BCVA improved by $0.30-0.70 \log$ MAR units, with a significant mean improvement of $0.45 \log$ MAR units (figure 4). Macular oedema improved in all patients by fluorescein angiography and/or OCT.

The current recommendation for a patient with a newly diagnosed BRVO is observation for 3 months because patients may show spontaneous improvement in vision during this period. If no improvement occurs and fluorescein angiography shows leakage in the macular area responsible for the decrease in vision, treatment with macular grid argon laser may result in improvement of visual acuity. The Branch Vein Occlusion Study ${ }^{4}$ demonstrated that $65 \%$ of laser-treated eyes gained two or more lines of vision, compared with $37 \%$ of untreated eyes after 3 years of follow-up. However, grid laser treatment was of limited benefit in many cases and may not be appropriate in patients with intraretinal haemorrhages that interfere with photocoagulation. ${ }^{4}$ Complications include enlargement of laser scars, choroidal neovascularisation, subretinal fibrosis and loss of visual field sensitivity. ${ }^{6-9}$ Because of these limitations, alternative treatments have been explored including intravitreal triamcinolone acetonide ${ }^{10-15}$ administration of intravitreal antiVEGF therapy, ${ }^{16}$ cannulation of vein branches, ${ }^{17}$ pars plana vitrectomy alone, ${ }^{18} 19$ pars plana vitrectomy with arteriovenous sheathotomy ${ }^{1-3} 20-26$ and laser-induced formation of chorioretinal anastomoses. ${ }^{27}$

Occlusions of branch retinal veins occur at arteriovenous crossing sites where the vein and artery share a common adventitial sheath. The pathogenic mechanism is thought to be 
Figure 4 Visual outcomes. Mean bestcorrected visual acuity (BCVA) immediately before surgery and at postoperative months $1,3,6,9$ and 12 are demonstrated with error bars representing $95 \% \mathrm{CI}$. Mean BCVA at 12 month postoperatively was significantly improved $(p=0.01)$ compared with baseline. Snellen BCVA was converted to logarithmic minimal angle resolution before analysis. Snellen BCVA equivalents and $p$ values for mean visual acuity improvement compared with baseline are demonstrated for each time period.

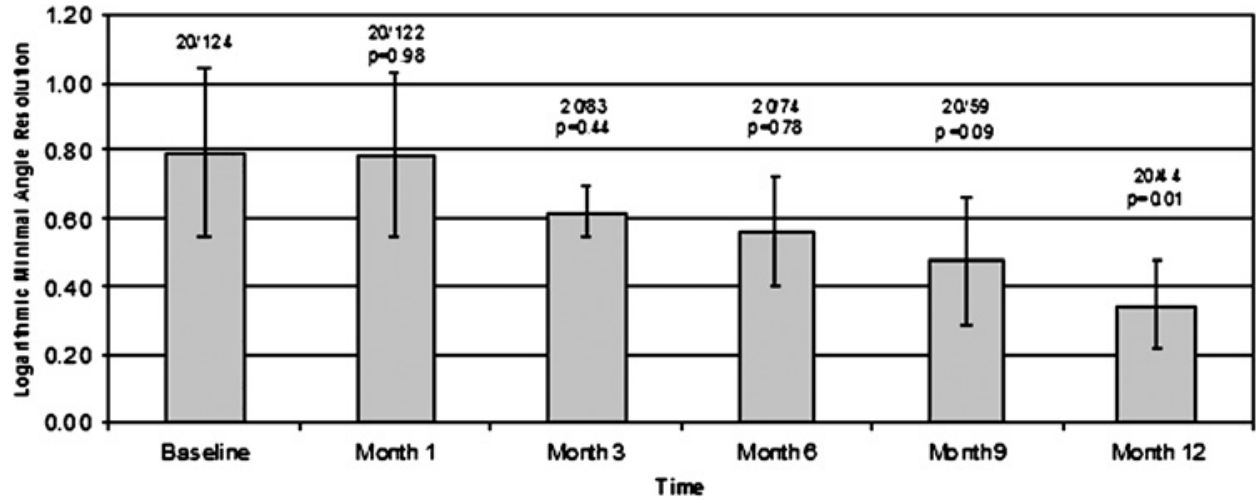

due to chronic hypertension and arteriosclerosis, which can lead to hypertrophy of the arterial wall with secondary venule compression and downstream turbulence that may result in endothelial injury and secondary thrombosis. ${ }^{28}$ Pars plana vitrectomy and arteriovenous sheathotomy is performed to section the sheath surgically, which is thought to decompress the vein and consequently improve macular oedema and capillary non-perfusion. In 1988, Osterloh and Charles ${ }^{20}$ described the first use of arteriovenous sheathotomy in a patient with a 3week history of BRVO who demonstrated BCVA improvement from $20 / 200$ to $20 / 25$ and progressive resolution of macular oedema and intraretinal haemorrhage at 8 months follow-up. Since this initial report, a number of studies employing different designs and surgical approaches have described encouraging outcomes with arteriovenous sheathotomy for BRVO. ${ }^{1-3} 21-26$ The surgical technique remains investigational and many factors including optimal case selection remain unclear. The effectiveness of arteriovenous sheathotomy is currently being investigated by the European Arteriovenous Sheathotomy Trial (EAST) in two prospective, randomised, controlled clinical studies at 10 European centres including Germany, Spain and Austria.

The precise mechanism by which arteriovenous sheathotomy leads to the resolution of macular oedema in BRVO remains controversial and may result from other components of the procedure. ${ }^{19}$ Vitrectomy alone may relieve vitreous traction along the macula that promotes fluid accumulation. It may also reduce inner retinal ischaemia by allowing oxygenated fluid to circulate in the vitreous cavity. Internal limiting membrane removal may also be beneficial. ${ }^{25}$ Kumagi et al ${ }^{19}$ evaluated the long-term outcomes of vitrectomy alone compared with vitrectomy with arteriovenous sheathotomy for macular oedema secondary to BRVO in 36 patients with symptoms up to 8 weeks in duration. The prospective, randomised study did not detect any significant difference in BCVA or foveal thickness at any postoperative period, with mean follow-up of 31 months (range 12-45 months). However, subgroup analysis of patients with symptoms for less than 4 weeks identified a trend $(p=0.064)$ towards better visual outcomes in the arteriovenous sheathotomy group. This suggests that arteriovenous sheathotomy may provide an additional benefit beyond that of vitrectomy and that appropriate case selection may be critical.

The use of intravitreal corticosteroids has increased in popularity as an alternative to imperfect conventional treatments for macular oedema associated with a broad range of retinovascular diseases, including diabetic retinopathy, ${ }^{29}$ central retinal vein occlusion, ${ }^{30}$ uveitis, ${ }^{31}$ exudative age-related macular degenera- tion $^{32}$ and pseudophakic cystoid macular oedema. ${ }^{33}$ Numerous studies in the literature have demonstrated promising outcomes with intravitreal triamcinolone acetonide treatment for macular oedema due to BRVO. ${ }^{10-15}$ Although steroids have anti-angiogenic, anti-fibrotic, and anti-permeability properties, the principal effects of steroids are stabilisation of the blood-retinal barrier, resorption of exudation and downregulation of inflammatory stimuli. ${ }^{34}$

The longevity and degree of visual acuity improvements associated with intravitreal triamcinolone acetonide treatment is difficult to assess given the limitations of many published studies, which include small numbers of treated patients, limited follow-up duration and lack of randomised controls. However, the National Eye Institute funded a multicentre, randomised study called the Standard Care versus Corticosteroid for Retinal Vein Occlusion (SCORE) study ${ }^{55}$ to evaluate the safety and efficacy of intravitreal triamcinolone acetonide compared with the standard of care treatment of macular oedema secondary to BRVO. That study demonstrated no visual acuity difference at 12 months for the standard care group compared with the triamcinolone groups ( $1 \mathrm{mg}$ and $4 \mathrm{mg}$ doses), but identified higher rates of elevated intraocular pressure and cataract formation in the $4 \mathrm{mg}$ group. Other smaller studies suggest that maximal efficacy with intravitreal triamcinolone acetonide may require multiple injections, ${ }^{15}$ and gains in visual acuity may be significant in the short term but may not result in permanent functional improvement. In a retrospective review of 13 eyes of 13 patients who underwent intravitreal triamcinolone acetonide for macular oedema due to BRVO, Cekic et al ${ }^{10}$ reported significant improvements in median visual acuity at last follow-up (range 4-24 months). However, only four of eight patients with at least 12 months follow-up demonstrated long-term visual acuity improvement. Three of these four patients underwent cataract extraction during the study period, confounding the interpretation of intravitreal triamcinolone acetonide efficacy. Macular oedema was improved in all five patients with at least 12 months follow-up who underwent OCT testing (five of eight patients), including three patients with visual acuity improvement. In a prospective study of 18 eyes of 18 patients who underwent intravitreal triamcinolone acetonide for macular oedema in non-ischaemic central retinal vein occlusion, Williamson and O'Donnell ${ }^{36}$ reported significant short-term improvements in visual acuity and macular oedema that were not sustained at 12 months despite repeat injections. No clinical cataract progression was noted during the study but one patient underwent cataract extraction after the study. Chen et a ${ }^{11}$ conducted a prospective study of 18 eyes of 18 patients who 
underwent intravitreal triamcinolone acetonide for macular oedema associated with BRVO and foveal ischaemia. The authors identified significant short-term gain in visual acuity at 1 month and decreased central macular thickness at 1 and 3 months. However, these early improvements disappeared at 6, 9 and 12 months follow-up. Posterior subcapsular cataract formation was noted in eight patients, six of which were noted at 12 months. In a prospective series of 13 eyes of 13 patients who underwent intravitreal triamcinolone acetonide for macular oedema secondary to vein occlusions, Patel et al ${ }^{13}$ reported only transient benefits with intravitreal triamcinolone acetonide and no improvement in BCVA or macular oedema after 12 months despite repeated injections. No significant cataracts were noted at the end of follow-up. Collectively, these reports suggest that intravitreal triamcinolone acetonide is an effective short-term treatment but by itself may not provide long-term benefits for macular oedema secondary to vein occlusions. Reported complications arising from intravitreal triamcinolone acetonide include steroid-induced ocular hypertension in one-third to more than one-half of patients. ${ }^{37-39}$ In our small series, we did not encounter any rise in intraocular pressure that required pharmacological intervention.

Combination therapy with intravitreal triamcinolone acetonide in conjunction with other treatment modalities may provide synergistic therapeutic benefits. This approach has been successful in other retinal diseases such as exudative age-related macular degeneration with the use of combined photodynamic therapy and intravitreal triamcinolone acetonide. The synergy may occur because intravitreal triamcinolone acetonide attenuates the pro-inflammatory and vasogenic sequelae of photodynamic therapy. ${ }^{40}$ Similarly, combining intravitreal triamcinolone acetonide with arteriovenous sheathotomy may produce a synergistic effect. Arteriovenous sheathotomy undoubtedly causes minor trauma to the retinal tissue, even when performed by expert retinal surgeons. The common arteriovenous wall can be as thin as 15 microns ${ }^{17}$ and reported iatrogenic complications include postoperative vitreous haemorrhage $e^{22}$ and localised retinal detachment ${ }^{3}$ originating from the arteriovenous sheathotomy site. Intraoperative intravitreal triamcinolone acetonide may quell postoperative inflammatory changes at the arteriovenous sheathotomy site in addition to its known antivasogenic benefits. The administration of intravitreal triamcinolone acetonide may also counteract the pro-inflammatory effects of interleukin 6, which has been inversely correlated with functional and anatomical improvements in vitreous samples recovered during arteriovenous sheathotomy. ${ }^{41}$

To our knowledge, there have been no previous studies demonstrating the efficacy of concomitant intraoperative intravitreal triamcinolone acetonide and vitrectomy with arteriovenous sheathotomy in the treatment of macular oedema due to BRVO. The cases presented exhibited marked improvements in acuity, as well as angiographic and OCT evidence of improvement in macular oedema. The study is limited by its small sample size, retrospective nature and lack of a control group. In addition, the decision for early intervention in case 3 , in which the patient was essentially monocular, confounds interpretation because macular oedema may improve spontaneously with observation. However, the promising results in this series suggest that combined intraoperative intravitreal triamcinolone acetonide and arteriovenous sheathotomy may improve visual and anatomical outcomes in patients with BRVO and further study is warranted.

Funding This study was supported by unrestricted funds from Research to Prevent Blindness, 645 Madison Avenue, Floor 21, New York, NY 10022-1010, USA.
Competing interests None declared.

Ethics approval This study was conducted with the approval of the New York Presbyterian Hospital Institutional Review Board.

Provenance and peer review Not commissioned; externally peer reviewed.

\section{REFERENCES}

1. Mason J 3rd, Feist R, White M Jr, et al. Sheathotomy to decompress branch retinal vein occlusion: a matched control study. Ophthalmology 2004;111:540-5.

2. Shah GK. Adventitial sheathotomy for treatment of macular edema associated with branch retinal vein occlusion. Curr Opin Ophthalmol 2000;11:171-4.

3. Cahill MT, Kaiser PK, Sears JE, et al. The effect of arteriovenous sheathotomy on cystoid macular oedema secondary to branch retinal vein occlusion. $\mathrm{Br} \mathrm{J} \mathrm{Ophthalmol}$ 2003;87:1329-32

4. Anon. The Branch Vein Occlusion Study Group. Argon laser photocoagulation for macular edema in branch vein occlusion. Am J Ophthalmol 1984:98:271-82.

5. Scott IU, Ip MS, VanVeldhuisen PC, et al. SCORE Study Research Group. A randomized trial comparing the efficacy and safety of intravitreal triamcinolone with standard care to treat vision loss associated with macular edema secondary to branch retinal vein occlusion: the Standard Care vs Corticosteroid for Retinal Vein Occlusion (SCORE) study report 6. Arch Ophthalmol 2009;127:1115-28.

6. Schatz H, Madeira D, McDonald HR, et al. Progressive enlargement of laser scars following grid laser photocoagulation for diffuse diabetic macular edema. Arch Ophthalmol 1991:109:1549-51.

7. Lewis $\mathbf{H}$, Schachat AP, Haimann MH, et al. Choroidal neovascularization after laser photocoagulation for diabetic macular edema. Ophthalmology 1990;97:503-10.

8. Guyer DR, D'Amico DJ, Smith CW. Subretinal fibrosis after laser photocoagulation for diabetic macular edema. Am J Ophthalmol 1992;113:652-6.

9. Striph GG, Hart WM Jr, Olk RJ. Modified grid laser photocoagulation for diabetic macular edema: the effect on the central visual field. Ophthalmology 1988;95:1673-167.

10. Cekic 0, Chang S, Tseng JJ, et al. Intravitreal triamcinolone injection for treatment of macular edema secondary to branch retinal vein occlusion. Retina 2005;25:851-5.

11. Chen SD, Sundaram V, Lochhead J, et al. Intravitreal triamcinolone for the treatment of ischemic macular edema associated with branch retinal vein occlusion. $A m \mathrm{~J}$ Ophthalmol 2006;141:876-83.

12. Jonas JB, Akkoyun I, Kamppeter B, et al. Branch retinal vein occlusion treated by intravitreal triamcinolone acetonide. Eye 2005;19:65-71.

13. Patel PJ, Zaheer I, Karia N. Intravitreal triamcinolone acetonide for macular oedema owing to retinal vein occlusion. Eye 2008;22:60-4.

14. Chung EJ, Lee H, Koh HJ. Arteriovenous crossing sheathotomy versus intravitreal triamcinolone acetonide injection for treatment of macular edema associated with branch retinal vein occlusion. Graefes Arch Clin Exp Ophthalmol 2008;246:967-74.

15. Lee H, Shah GK. Intravitreal triamcinolone as primary treatment of cystoid macular edema secondary to branch retinal vein occlusion. Retina 2005;25:551-5.

16. Rabena MD, Pieramici DJ, Castellarin AA, et al. Intravitreal bevacizumab (Avastin) in the treatment of macular edema secondary to branch retinal vein occlusion. Retina 2007:27:419-25

17. Tang WM, Han DP. A study of surgical approaches to retinal vascular occlusions. Arch Ophthalmol 2000;118:138-43.

18. Saika S, Tanaka T, Miyamoto T, et al. Surgical posterior vitreous detachment combined with gas/air tamponade for treating macular edema associated with branch retinal vein occlusion: retinal tomography and visual outcome. Graefes Arch Clin Exp Ophthalmol 2001;239:729-32.

19. Kumagai K, Furukawa M, Ogino N, et al. Long-term outcomes of vitrectomy with or without arteriovenous sheathotomy in branch retinal vein occlusion. Retina 2007:27:49-54.

20. Osterloh MD, Charles S. Surgical decompression of branch retinal vein occlusions. Arch Ophthalmol 1988;106:1469-71.

21. Lerche RC, Richard G. Arteriovenous sheathotomy in venous thrombosis. Klin Monatsbl Augenheilkd 2004;221:479-84.

22. Le Rouic JF, Bejjani RA, Rumen F, et al. Adventitial sheathotomy for decompression of recent onset branch retinal vein occlusion. Graefes Arch Clin Exp Ophthalmol 2001;239:747-51.

23. Opremcak EM, Bruce RA. Surgical decompression of branch retinal vein occlusion via arteriovenous crossing sheathotomy: a prospective review of 15 cases. Retina 1999;19:1-5.

24. Shah GK, Sharma S, Fineman MS, et al. Arteriovenous adventitial sheathotomy for the treatment of macular edema associated with branch retinal vein occlusion. Am J Ophthalmol 2000;129:104-6.

25. Mester U, Dillinger $P$. Vitrectomy with arteriovenous decompression and internal limiting membrane dissection in branch retinal vein occlusion. Retina 2002;22:740-6.

26. Stoffelns BM, Kramann C, Schoepfer K. Arteriovenous crossing sheathotomy in branch retinal vein occlusion. Klin Monatsbl Augenheilkd 2009;226:310-14.

27. Fekrat S, Goldberg MF, Finkelstein D. Laser-induced chorioretinal venous anastomosis for nonischemic central or branch vein occlusion. Arch Ophthalmol 1998;116:43-52. 
28. Kumar B, Yu DY, Morgan WH, et al. The distribution of angioarchitectural changes within the vicinity of the arteriovenous crossing in branch retinal vein occlusion. Ophthalmology 1998;105:424-7.

29. Martidis A, Duker JS, Greenberg PB, et al. Intravitreal triamcinolone for refractory diabetic macular edema. Ophthalmology 2002;109:920-7.

30. Greenberg PB, Martidis A, Rogers AH, et al. Intravitreal triamcinolone acetonide for macular oedema due to central retinal vein occlusion. $\mathrm{Br} J$ Ophthalmol 2002; 86:247-8

31. Helm CJ, Holland GN. The effects of posterior subtenon injection of triamcinolone acetonide in patients with intermediate uveitis. Am J Ophthalmol 1995;120:55-64.

32. Danis RP, Ciulla $T A$, Pratt $L M$, et al. Intravitreal triamcinolone acetonide in exudative age-related macular degeneration. Retina 2000;20:244-50.

33. Melberg NS, Olk RJ. Corticosteroid-induced ocular hypertension in the treatment of aphakic or pseudophakic cystoid macular edema. Ophthalmology 1993;100:164-7.

34. Wilson CA, Berkowitz BA, Sato Y, et al. Treatment with intravitreal steroid reduces blood-retinal barrier breakdown due to retinal photocoagulation. Arch Ophthalmol 1992:110:1155-9
35. Scott IU, Ip MS. It's time for a clinical trial to investigate intravitreal triamcinolone for macular edema due to retinal vein occlusion: the SCORE study. Arch Ophthalmol 2005; 123:581-2.

36. Williamson TH, O'Donnell A. Intravitreal triamcinolone acetonide for cystoid macular edema in nonischemic central retinal vein occlusion. Am J Ophthalmol 2005;139:860-6.

37. Jonas JB, Degenring RF, Kreissig I, et al. Intraocular pressure elevation after intravitreal triamcinolone acetonide injection. Ophthalmology 2005;112:593-8

38. Smithen LM, Ober MD, Maranan L, et al. Intravitreal triamcinolone acetonide and intraocular pressure. Am J Ophthalmol 2004;138:740-3.

39. Bakri SJ, Beer PM. The effect of intravitreal triamcinolone acetonide on intraocula pressure. Ophthalmic Surg Lasers Imaging 2003:34:386-90.

40. Spaide RF, Sorenson J, Maranan L. Combined photodynamic therapy with verteporfin and intravitreal triamcinolone acetonide for choroidal neovascularization. Ophthalmology 2003:110:1517-25.

41. Shimura M, Nakazawa T, Yasuda K, et al. Visual prognosis and vitreous cytokine levels after arteriovenous sheathotomy in branch retinal vein occlusion associated with macular oedema. Acta Ophthalmol 2008;86:377-84 